\title{
The First Stereospecific Catalytic Hydrogenation with a Polymer Supported Optically Active Rhodium Complex U. Nagel* and E. Kinzel
}

\author{
Institut für Anorganische Chemie der Universität, Meiserstrasse 1, D-8000 München 2, West Germany
}

Optical yields up to $100 \%$ are obtained in the heterogeneous hydrogenation of $\alpha$-(acetylamino)cinnamic acid and its methyl ester in the presence of rhodium complexes of 3,4-(R,R)-bis(diphenylphosphino)pyrrolidine, bound covalently to silica.

While heterogeneous catalysis is important in many fields of chemistry, there are only a few examples of this technique in the production of optically active molecules. The highest optical yield in heterogeneous catalytic hydrogenation reported to date was achieved with a rhodium alanine complex, bound to a polymer containing aldehyde groups. ${ }^{1}$ In the homogeneous catalytic hydrogenation of $\alpha$-(acetylamino)cinnamic acid and its derivatives, rhodium complexes of diphosphines generally give high enantiomeric excesses (e.e.s).2,3 Two such catalysts with DIOP [2,2-dimethyl-4,5-bis(diphenylphosphinomethyl)-1,3-dioxolane] and PPM \{4-(diphenylphosphino)-2-[(diphenylphosphino)methyllpyrolidine? as ligands have been bound to poly(hydroxyethyl methacrylates). ${ }^{4} 6$ The polymer bound complexes gave optical yields comparable to their soluble counterparts. Enantiomeric purities up to $100 \%$ have been obtained with rhodium complexes of 1,2-diphosphines, ${ }^{7-10}$ yet none of them have been fixed an a polymer, because they lack a functionality for this purpose. Recently we synthesized 3,4-(R,R)bis(diphenylphosphino)pyrrolidine (1);11 below we describe the fixation of rhodium complexes of this ligand an silica and some results in the catalytic hydrogenation of $\alpha$-(acetylamino)cinnamic acid and its methyl, ester with these complexes.

The reaction of 1-amino-3-(triethoxysilyl)propane with a dicarboxylic acid derivative (diethyl oxalate, diphenyl terephthalate, glutaric acid anhydride) gives the monoamides (2). The glutaric acid monoamide is converted into the penta-

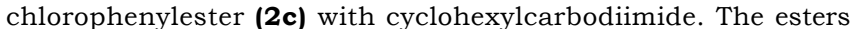
(2) react with (1) to give the silyl derivatives (3). These afford with bis(cyclo-octa-1,5-diene)rhodium tetrafluoroborate, [(cod) $\left.)_{2} \mathrm{Rh}\right]-$ $\mathrm{BF}_{4}$, the rhodium complexes (4) which react in $\mathrm{CH}_{2} \mathrm{Cl}_{2}$, toluene, or $\mathrm{MeOH}$ with silica of different pore size to give the catalysts (5). The silica samples used were Merck No. 10181 (pore size 4nm), No. $7733(6 \mathrm{~nm})$, and No. $10185(1 \mathrm{Onm})$. To avoid the breakdown of the silica particles, the suspensions were agitated, not stirred. In some preparations the sequence of the steps was altered without a change in the product. The silica bound complexes were washed with $\mathrm{MeOH}$ for a few hours until the filtrates became colourless. To estimate the amount of fixed rhodium the combined filtrates were reduced to dryness in vacuo. The signal of the phenylic protons in the ${ }^{1} \mathrm{H}$ n.m.r. spectrum of the residue was integrated against a standard and the rhodium content of the catalysts calculated. The maximum amount of rhodium fixable is about $20 \mu \mathrm{mol}$ Rh per g silica, normally 5-20 $\mu \mathrm{mol}$ corresponding to a monolayer of about $10 \mathrm{~m}^{2}$. Silica has a surface between 200 and $800 \mathrm{~m}^{2} / \mathrm{g}^{12}$ Some of the pores in the silica may be too small for the relatively large (about $2 \mathrm{~nm}$ ) complex.

The catalysts were used for the hydrogenation of $\alpha$-(acetylamino)cinnamic acid and its methyl ester in methanolic solution (Table 1). The optical yields were comparable to the homogeneous case although they varied considerably with silica of different pore size with the ester as substrate; this was not observed with the acid. The longer and more flexible the link between the silica and (1) is, the higher is the optical purity of the resulting (S)-N-acetylphenylalanine. Up to $100 \%$ e.e. was achieved with the dehydro amino acid ester, 97\% with the acid as substrate. If the coupling an the silica was done in $\mathrm{CH}_{2} \mathrm{Cl}_{2}$ instead of $\mathrm{MeOH}$, the resulting catalyst was much less active for the hydrogenation of $\alpha$-(acetylamino)cinnamic acid, even though it was washed thoroughly with $\mathrm{MeOH}$. This effect is more pronounced if diethoxydimethylsilane is added during the coupling. In $\mathrm{MeOH}$ the coupling between (4a-c) and silica is a simple condensation of surface hydroxy groups of the silica with the ethoxysilyl groups of (4) and the rhodium side of the molecule remains cationic and solvated. The silane free analogue of (4b) [(3R,4R)-1-benzoyl-3,4-bis(diphenylphosphino)pyrrolidine-P, $\left.\mathrm{P}^{\prime}\right]$ (cyclo-octa-1,5-diene)rhodium tetrafluoroborate ${ }^{11}$ does not react with silica in $\mathrm{MeOH}$. In $\mathrm{CH}_{2} \mathrm{C}_{2}$ Or toluene the rhodium cation is probably adsorbed onto the silica before the condensation takes place yielding another surface 
Table 1. Asymmetric hydrogenation catalysed

\begin{tabular}{|c|c|c|c|c|c|}
\hline Catalyst & $\begin{array}{l}\text { Pore size } \\
\text { (nm) }\end{array}$ & Substrate & $\begin{array}{r}\text { Substrate/ } \\
\text { Catalyst } \\
\text { (molarratio) }\end{array}$ & $\begin{array}{l}\text { Turnoverb } \\
\left(\mathrm{min}^{-1}\right)\end{array}$ & $\begin{array}{r}\text { E.e. }^{\circ} \\
(\%)\end{array}$ \\
\hline (5a) & 10 & acid & 2200 & 5 & 93 \\
\hline$(5 a)^{d}$ & 10 & acid & 2200 & 1.5 & 93 \\
\hline$(5 a)^{e}$ & 10 & acid & 2200 & $1-0.2$ & 87 \\
\hline (5b) & 4 & acid & 600 & 0.6 & 93 \\
\hline (5b) & 6 & acid & 950 & 1 & 93 \\
\hline (5b) & 10 & acid & 1050 & 0.25 & 91 \\
\hline (5b) & 4 & ester & 650 & 0.4 & 100 \\
\hline (5b) & 10 & ester & 500 & 0.1 & 89 \\
\hline$(5 c)^{f}$ & 6 & acid & 2500 & 1 & 94 \\
\hline$(5 c)^{g}$ & 6 & acid & 2250 & 8 & 95 \\
\hline$(5 c)^{\text {th }}$ & 6 & acid & 2500 & 0.5 & 95 \\
\hline$(5 c)^{g, h}$ & 6 & acid & 1750 & 6 & 97 \\
\hline
\end{tabular}

${ }^{a}$ Solvent: $15 \mathrm{ml} \mathrm{MeOH} ; \mathrm{P}\left(\mathrm{H}_{2}\right)$ : 50-40 atm; temperature: $22{ }^{\circ} \mathrm{C}$; chemical yield quantitative; substrate: $\alpha$-(acetylamino)cinnamic acid or ester. ${ }^{\mathrm{b}}$ Roughly estimated from the pressure drop of the autoclave after $50 \%$ reaction. ${ }^{c}$ Ee. $=$ Enantiomeric excess. ${ }^{\mathrm{d}}$ Catalyst from first run, reused. ${ }^{\mathrm{e}}$ Catalyst reused a second time, stored in air for a short time before use. ${ }^{\mathrm{f}}$ Prepared in $\mathrm{CH}_{2} \mathrm{Cl}_{2} .{ }^{\mathrm{g}}$ Prepared in $\mathrm{MeOH}$. ${ }^{\mathrm{h}}$ With added diethoxydimethylsilane.

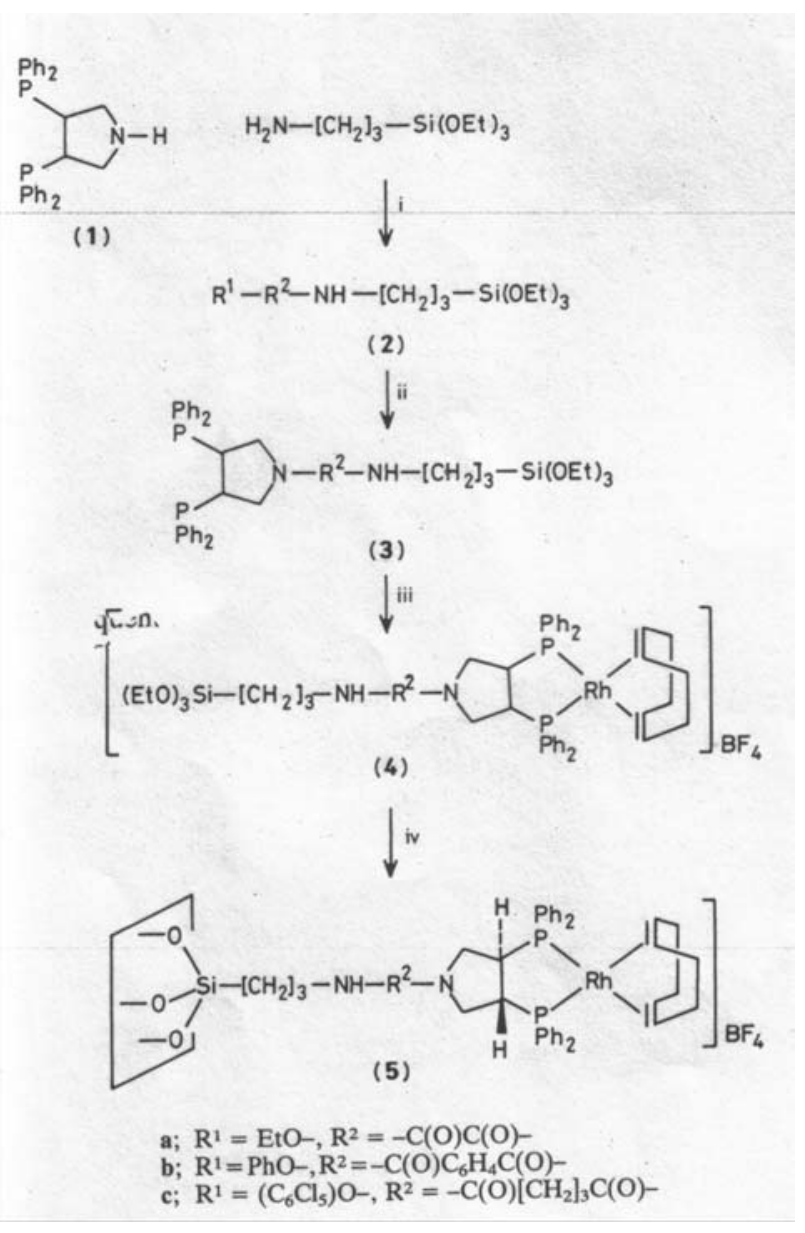

Scheure 1. Reagents: $i$, a EtOC $(\mathrm{O}) \mathrm{C}(\mathrm{O}) \mathrm{OEt}, \mathrm{b}$ PhOC(O) $\mathrm{C}_{6} \mathrm{H}_{4^{-}}$ $\mathrm{C}(\mathrm{O}) \mathrm{OPh}$, c (1) ( $\mathrm{H}_{2} \mathrm{C}(\mathrm{O}) \mathrm{OC}(\mathrm{O}) \mathrm{CH}_{2} \mathrm{CH}_{2}$, (2) $\mathrm{C}_{6} \mathrm{Cl}_{5} \mathrm{OH}+$ $\mathrm{C}_{6} \mathrm{H}_{11} \mathrm{~N}=\mathrm{C}==\mathrm{NC}_{6} \mathrm{H}_{11} ; \mathrm{ii},(1) ; \mathrm{iii},\left[(\mathrm{cod})_{2} \mathrm{Rh}_{2} \mathrm{BF}_{4}\right.$; iv, surface hydroxy groupsof silica. geometry where the rhodium atoms are much more shielded, especially when diethoxydimethylsilane is added because then a protective silicone film is formed an the surface of the silica. Since it seems this geometry is stable against $\mathrm{MeOH}$ during washing and hydrogenation, the complexes fixed in $\mathrm{CH}_{2} \mathrm{Cl}_{2}$ are less accessible and less active. The addition of diethoxydimethylsilane improves the mechanical stabilityof the silica. The maximum rate of the hydrogenation is about four times slower than in solution, probably due to slow diffusion in the silica particles of $0.2-0.5 \mathrm{~mm}$ size. In two cases the catalyst was reused three times. The molar ratio substrate : catalyst was 2200 in every run; in the third run the activity decreased considerably with some loss of selectivity, probably caused by oxidation. ${ }^{4}$ In the homogeneous hydrogenation with (1), the maximum ratio substrate : catalyst is about 10000 , the selectivity in this case remains $99 \%$ as long as the catalyst is active. ${ }^{11}$

We are grateful to Professor W. Beck for discussions and to Degussa AG, Hanau for financial support.

Received, 13th January 1986; Com. 054

\section{References}

1 L. M. Koroleva, Candidate's Thesis in Chemical Sciences, Institute of Organoelemental Compounds, U.S.S.R. Academy of Sciences, Moscow, 1980; E. 1. Klabunovskii, Russ. Chem. Rev. (Engl. Transl.), 1982, 51,630.

2 T. P. Dang and H. B. Kagan, J. Chem. Soc., Chem. Commun., 1971,481.

3 K. Achiwa, J. Am. Chem. Soc., 1976, 98, 8265.

4 N. Takaishi, H. Imai, C. A. Bertelo, and J. K. Stille, J. Am. Chem. Soc., 1978, 100, 264.

5 K. Achiwa, Chem. Lett., 1978, 905.

6 G. L. Baker, S. J. Fritschel, J. R. Stille, and J. K. Stille, J. Org. Chem., 1981, 46, 2954.

7 B. D. Vineyard, W. S. Knowles, M. J. Sabacky, G. L. Bachman, and D. J. Weinkauff, J. Am. Chem. Soc., 1977, 99, 5946.

8 M. D. Fryzuk and B. Bosnich, J. Am. Chem. Soc., 1977,99, 6262. 9 D.

L. Allen, V. C. Gibson, M. L. H. Green, J. F. Skinner, J. Bashkin, and P. D. Grebenik, J. Chem. Soc., Chem. Commun., 1983,895 .

10 H. Brunner and W. Pieronczyk, Angew. Chem., 1979,91,655:11 U. Nagel, Angew. Chem., 1984, 96,425.12 'Uilmanns Encyklopädie der technischen Chemie', Vol.'

Verlag Chemie, Weinheim, 1982, pp. 458-469. 